\title{
EXPERIMENTAL REFERRED PAIN FROM THE GASTRO- INTESTINAL TRACT. PART I. THE ESOPHAGUS
}

\author{
By W. S. POLLAND aNd A. L. BLOOMFIELD
}

(From the Department of Medicine, Stanford University School of Medicine, San Francisco)

(Received for publication March 30, 1931)

Despite the development of modern diagnostic methods, the exact recognition of the disorders or lesions which are responsible for digestive symptoms remains a difficult problem. In practice the percentage of error in this domain of medicine is high and in many instances diagnosis is based more on the general clinical intuition of the examiner than on any very substantial basis. The interpretation of symptoms is especially difficult and it is with this phase of the subject that the present studies are concerned.

It is generally conceded that the first step in the analysis of a digestive disorder is a careful consideration of the patient's history, and symptom complexes have been built up which are believed by some to indicate with considerable certainty the existence of special lesions. Many physicians, for example, are quite dogmatic as to the significance of so-called "peptic ulcer indigestion" or "gallbladder indigestion"; some go even further and feel that such conditions as "duodenitis," "mobile cecum," etc., present themselves with characteristic complaints. The validity of such symptom complexes, however, still remains open to question and our own experience indicates that unless fortified by some highly specific phenomenon such as bleeding in the case of ulcer or colic or jaundice in the case of gallbladder disease, the digestive symptoms in themselves (gas, vague abdominal distress, burning or "indigestion") have little, if any, specific meaning. When one considers that the upper abdominal viscera have a common autonomic innervation and that their sensibility under ordinary conditions is of a crude protopathic type this conclusion is supported. Furthermore, when one interrogates patients with digestive dis- 
comforts and in response to the question is the pain dull, knife-like, radiating, cramp-like, diffuse or localized, almost always receives an equivocal answer it becomes evident that efforts to draw exact conclusions from minute differences in types of discomfort rest on an unsound basis.

To this statement exception must be made with reference to two clearly defined and intelligible types of pain-severe hollow viscus colic whether it be of renal, biliary or intestinal origin clearly indicates forcible contraction of the structure in question in response to obstructive or inflammatory spasm, and intense localized pain with tenderness on pressure with almost equal certainty points to an actual lesion of peritoneum. But these two types of sensation which are of great diagnostic value occur in only a negligible minority of the great run of patients with digestive symptoms and they do not bear directly, therefore, on the point now at issue. At any rate it is clear that the problem of the interpretation of digestive symptoms still requires solution, and as it has been impossible by means of clinical observation to settle the question an experimental approach is desirable. This seemed feasible at least insofar as one might stimulate artificially various parts of the digestive tract and observe the character and location of such sensations as were produced with reference to features of practical diagnostic value.

Our plan, in brief, was to produce pain by inflating balloons at various levels of the gastro-intestinal tract and to examine a sufficiently large series of people so that statistical conclusions could be drawn as to site of reference of pain, its character and the relation of artificially produced pain to spontaneous pain in patients with digestive symptoms. The present paper concerns itself with studies of the esophagus only; the stomach, duodenum and colon will be discussed in a later communication.

\section{LITERATURE}

It is a matter of common experience that under thoroughly normal conditions the activities of the gastro-intestinal tract are carried on with a minimum of conscious sensation. Aside from the vague discomfort of hunger and the indefinite feeling of "fullness" after eating little is to be felt and indeed even these sensations are bound up with a wider somatic reaction which is clearly not directly referable to the stomach. More purposeful attempts to analyze the sensibility of the gastro-intestinal tract 
In the main furnish confirmation of the essential silence of its operations as far as consciousness is concerned and the reader may be referred to the painstaking observations of Mackenzie (1), Hertz (2) and others, and later of Carlson. Carlson and Braafladt (3) in experiments in which the exact nature of the procedure was unknown to the subject observed that the normal stomach mucosa was insensitive to tactile stimuli, that there was a crude (protopathic) reaction to the extremes of heat $\left(45^{\circ} \mathrm{C}\right.$.) and cold $\left(12^{\circ} \mathrm{C}\right.$.) and that stimulation of the mucosa increased reflex excitability of the spinal cord and induced changes in vasomotor tonus. Hertz among other things pointed out that while the stomach was ordinarily insensible to heat, cold and the introduction of acid, the esophagus reacted to these stimuli with sensations referred to the lower sternal region and epigastrium. Such purposeful observations have been amplified from day to day in the clinic by surgeons who cut and handle the gastro-intestinal mucosa directly at operation or through the proctoscope.

As far as the present mode of attack is concerned but little has been done previously. Payne and Poulton (4) attempted to analyze the motility of the esophagus in relation to spontaneous pain in clinical cases by registering contractions transmitted through a water filled balloon. They showed among other things that the sensation of "heartburn" was associated with peristaltic movements of the esophagus. They subsequently elaborated their work $(5,6)$ and produced evidence that referred pain from the esophagus is caused by "stretching and deformity of the pain endings in the wall." Nausea was produced by distension of the esophagus as well as referred pain but they report no systematic studies on relation of the site of stimulation and the situation of the referred pain. Hertz (2) inflated the esophagus in two normal men by means of a thin rubber bag. There resulted a sensation of fullness "felt as if it were produced in the middle line deeply beneath the anterior surface of the body" and the level of the stimulus was always accurately recognized. C. M. Jones (7) has also carried out somewhat similar experiments but no really extensive data are available.

\section{APPARATUS AND METHODS}

The mercury weighted stomach tube described by Wilkins was used. A small balloon was constructed around the perforations proximal to the mercury chamber. Rubber from an ordinary toy balloon was found satisfactory and durable. The balloon was made in such a way that when collapsed its walls approximated those of the stomach tube, and when distended with $30 \mathrm{cc}$. of air it assumed an almost spherical shape with a diameter of about $3 \mathrm{~cm}$. The tube was marked at intervals so that the position of the bag in the esophagus could be readily estimated and it was attached by a $\mathrm{T}$ connection on the one hand to a $\mathbf{U}$ mercury manometer and on the other to a luer syringe. (See Fig. 1.) The procedure consisted 
of inflating the bag in the esophagus at various levels. We usually began at $20 \mathrm{~cm}$. from the teeth and advanced by intervals of $5 \mathrm{~cm}$. until the cardia was reached. Air was introduced by means of a $30 \mathrm{cc}$. luer syringe at the rate of $2 \mathrm{cc}$. per second (metronome) and the subject was requested to signal as soon as he felt anything, and to indicate, by pointing, the site of the sensation. The amount of air in the bag and the pressure were recorded at this point as well as the character of the sensation.

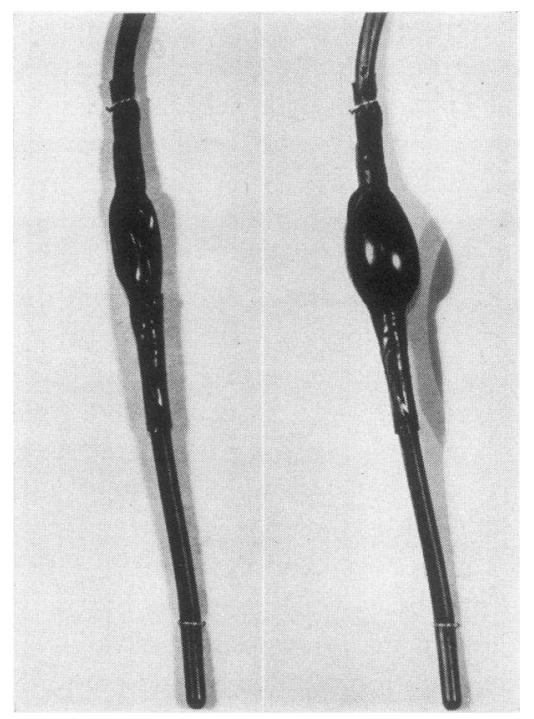

\section{Fig. 1. Balloon Used in Esophagus, Collapsed and Inflated}

The following points were studied: (1) The minimum amount of inflation (cc. of air and pressure) necessary to produce sensation, (2) the site of the sensation, (3) the character of the sensation, (4) the relation of site of sensation to position of balloon, (5) the relation of sensation to spontaneous clinical symptoms, and (6) the mechanism of the referred pain.

A miscellaneous group of ward patients were used; some had digestive symptoms, but for the most part they were free of gastro-intestinal trouble, The object of the experiment was explained and the patients cooperated. usually very intelligently.

\section{THE SITE OF THE SENSATION}

It soon became evident that there were sites of predilection for referred sensation regardless of the position of the bag (see below). These sites were at the lower end of the sternum and in the neck just 

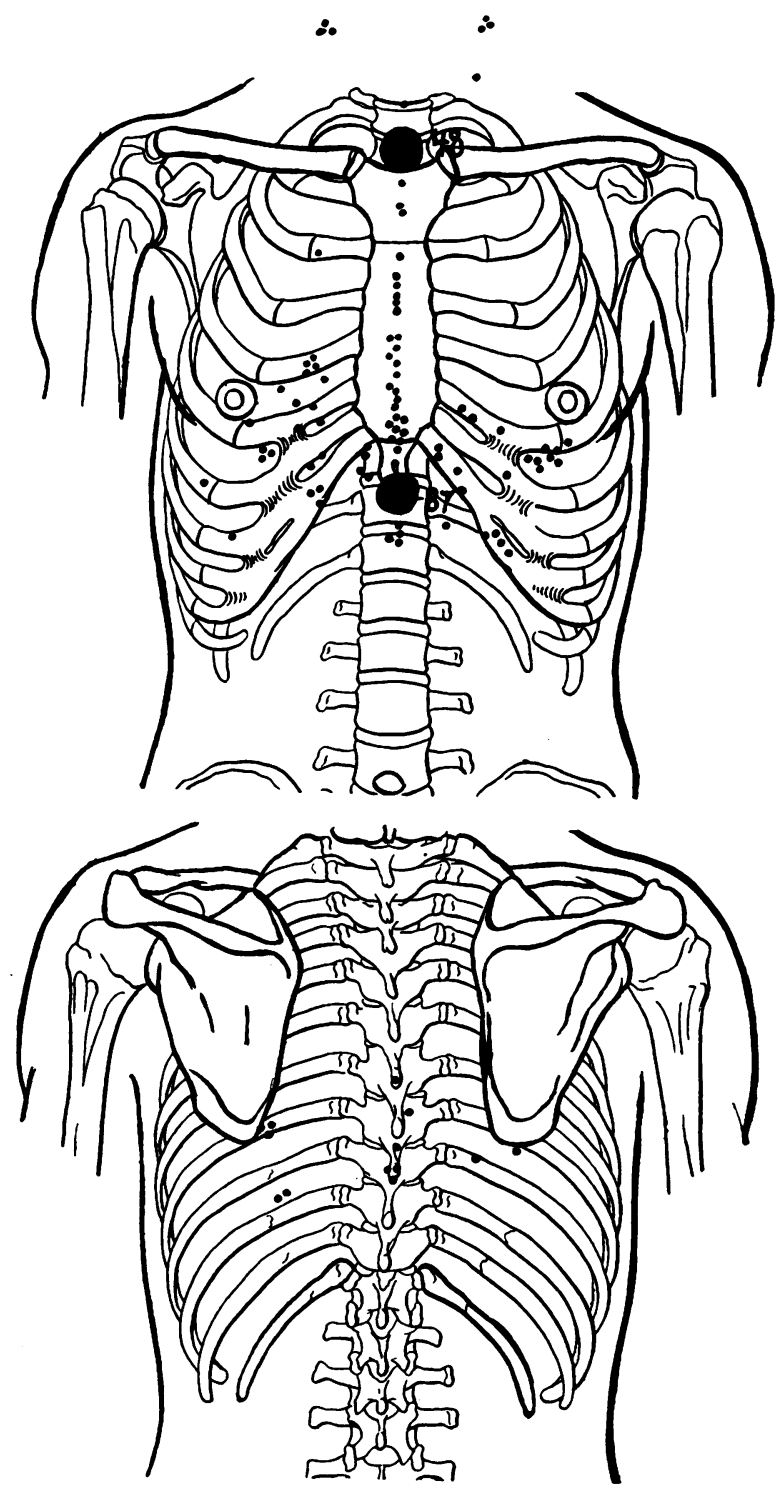

Fig. 2. Sites of Referred Pain from Inflation of Esophagus. Each dot indicates response to one inflation except the large circles which represent groups of 48 and 87 dots which fell too close for separate charting. 


\begin{tabular}{|c|c|c|c|c|c|c|}
\hline & 2 & 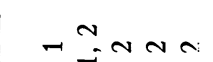 & बे & N & in $m+$ & \multirow{6}{*}{ 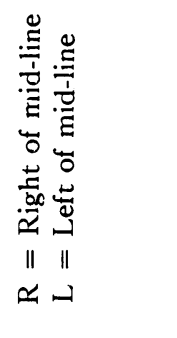 } \\
\hline & \multirow{2}{*}{$\stackrel{\infty}{\sim}$} & \multirow{2}{*}{$\operatorname{Nant}$} & $\infty$ & $N$ & $\sim 0$ & \\
\hline & & & m & $N$ & $\sim \stackrel{\alpha}{\sim} \sim$ & \\
\hline & $=$ & $\stackrel{\sim}{\sim} \sim N$ & : & $\sim$ & $N \sim N$ & \\
\hline & $\stackrel{0}{2}$ & $\tan$ in $N$ & $\ddot{m}$ & $\stackrel{\sim}{=}$ & $\begin{array}{l}\because \because-2 \\
4 N a n\end{array}$ & \\
\hline & 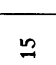 & $\cong \approx \sim N$ & & & 5 & \\
\hline 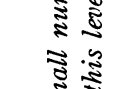 & \pm & 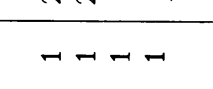 & 苛 & $\stackrel{a}{y}$ & ה点 & \\
\hline 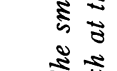 & $m$ & $\vec{A} \Delta \overrightarrow{\mathrm{N}}$ & $m$ & N & 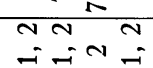 & \\
\hline$\widetilde{\Xi}$ & & N & లే & $m$ & $\ln N 0 \mathrm{~N}$ & \\
\hline 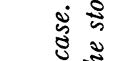 & $\simeq$ & 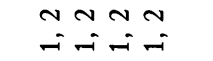 & - & - & נユルさ & \\
\hline $\overrightarrow{\tilde{z}} \tilde{a}$ & - & ルル & $m$ & $\stackrel{2}{\sim}$ & 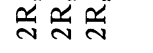 & \\
\hline 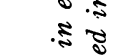 & -7 & 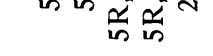 & 요 & $\frac{x}{y}$ & $\frac{\alpha}{x} \frac{\alpha}{y} \frac{\alpha}{4}$ & \\
\hline 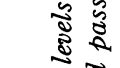 & 우 & 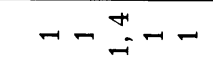 & बे & 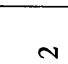 & När & $\Xi$ \\
\hline$\frac{3}{3}$ & $a$ & NN & & & i & 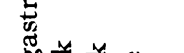 \\
\hline 告 & & & $\stackrel{\infty}{\sim}$ & $m$ & $\ln N$ & 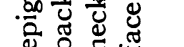 \\
\hline $\overrightarrow{0} \widetilde{\widetilde{z}}$ & $\infty$ & $\sim \sim \sim \vec{~}$ & $\hat{\sim}$ & + & in th in & \|\|\|\| \\
\hline$\Xi_{0}^{2}$ & n & $-N \stackrel{\frac{\alpha}{N}}{N}-$ & i & -1 & $+\hat{n}$ & $b \sim \infty a$ \\
\hline 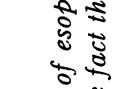 & $\bullet$ & $\sim \triangleq \vec{\sim}$ & $\curvearrowleft$ & $\sigma$ & $\stackrel{\sim}{i}$ & \\
\hline 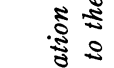 & n & 承 & & & $\begin{array}{l}m^{-} \\
\infty\end{array}$ & \\
\hline हू & & $+\frac{\alpha}{\gamma} N$ & $\stackrel{\text { a }}{2}$ & & $\operatorname{nnnI}$ & \\
\hline 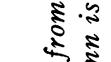 & + & ถ & $\tilde{\sim}$ & & $N \sim N$ & \\
\hline$\cdot \frac{8}{2}$ & $m$ & 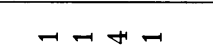 & ก & $m$ & 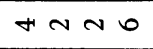 & \\
\hline$\vec{s} \tilde{s}$ & & & $\bar{N}$ & $\rightarrow$ & $m+N a$ & \\
\hline$\frac{1}{2}$ & $N$ & 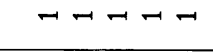 & & & $\omega^{2}$ & \\
\hline$\frac{2}{2}$ & - & 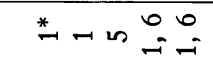 & శి & & 嵒言 & 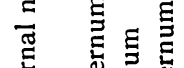 \\
\hline $\begin{array}{l}\text { ठ } \\
\text { है } \\
\text { है } \\
\text { जे }\end{array}$ & 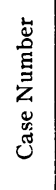 & 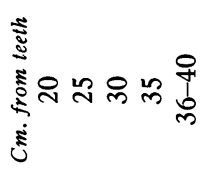 & 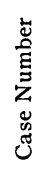 & 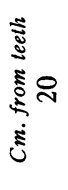 & 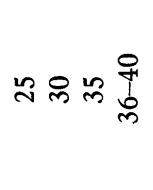 & 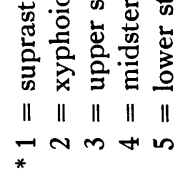 \\
\hline
\end{tabular}


above the suprasternal notch. As a rule the subject pointed definitely to one or another of these regions. However, other situations at various levels of the sternum to the left or right and in back were frequently indicated. Sometimes the subject pointed to two perhaps widely separated areas or first to one spot and then to another. It was evident that conditions of contraction or relaxation of the esophagus quite apart from the artificial stimulus might modify the referred sensation; this was brought out very clearly in many cases in which a repetition of the test after an interval of a few minutes yielded quite different results from the first experiment. Figure 2 shows graphically the total area implicated by all our experiments and Table I summarizes the findings in each case. The symbols indicate roughly the points at which pain was felt although it is not possible to bring out by this method the size of the area of referred sensation. R and L indicate that the pain spread from the mid-line either to right or left or that it was located entirely to right or left. Table II shows very clearly the

TABLE II

Summary of location of referred pain from inflation of esophagus at various levels

\begin{tabular}{c|r|r|r|r|r|r|r|r|r}
\hline \hline $\begin{array}{c}\text { Level of balloon } \\
\text { from teeth }\end{array}$ & \multicolumn{7}{|c|}{ Location of pain } \\
\cline { 2 - 7 } & 1 & 2 & 3 & 4 & 5 & 6 & 7 & 8 & $9 *$ \\
\hline$c m$. & & & & & & & & & \\
20 & 12 & 17 & 3 & 5 & 1 & 0 & 0 & 0 & 0 \\
25 & 9 & 19 & 2 & 4 & 6 & 0 & 2 & 0 & 0 \\
30 & 7 & 24 & 2 & 5 & 5 & 2 & 5 & 1 & 1 \\
35 & 8 & 19 & 0 & 2 & 3 & 3 & 2 & 0 & 0 \\
40 & 8 & 0 & 0 & 0 & 2 & 0 & 0 & 0 \\
\hline Total & 48 & 87 & 7 & 16 & 15 & 7 & 9 & 1 & 1 \\
\hline
\end{tabular}

* The numbers 1-9 have same meaning as in Table 1.

preponderance of suprasternal notch and xyphoid region as sites of pain, these two areas being implicated 135 times in 191 inflations. Next in frequency come other areas behind the sternum, with epigastrium, back, face and neck only occasionally affected. As pointed out above the sensation was usually vague and more or less widespread with a central point of maximum intensity. The diagrams must be 
interpreted with this in mind as it was impossible to outline accurately the exact and complete distribution of the referred sensations.

RELATION OF SITE OF SENSATION TO POSITION OF BALLOON

As pointed out above (see review of literature) some observers have concluded that pain from distension of the esophagus is referred to the body surface (sternum) at the level of the stimulus. Our observations were quite at variance with any such idea. This is clearly shown by Tables I and II and indeed there was only one case (Case 21) in which there appeared to be a constant relation between the site of the balloon and the referred sensation. The situation can best be clarified by diagrams of illustrative cases (Figures 3 to 9). It appears that with the balloon high in the esophagus pain may be referred to the xyphoid and vice versa, or that various permutations and combinations may occur. The occasional cases in which pain was referred to the face and high in the neck are of special interest, and also those instances in which the sensation lay definitely to one side of the mid-line. A possible explanation of this phenomenon will be discussed below; but the point of practical importance is that the site of pain does not indicate any definite site for the location of the stimulus.

The sensations so far described have been those which resulted from minimal stimuli; as soon as the subject felt anything the inflation was stopped and the pain was recorded. However, if further inflation was carried out the sensation might not only be accentuated at the original site but often spread widely or appeared in new situations. For example pain felt at first in the suprasternal notch on increased pressure spread up and down entire sternum and finally localized at the xyphoid, or, pain felt first $5 \mathrm{~cm}$. above xyphoid on increased pressure radiated to both shoulder blades. It is evident therefore, that no absolute effects can be expected but that endless variations will exist depending upon the intensity of the stimulus and the sensitiveness of the pain producing mechanism.

Even with stimuli as nearly as possible constant, repeated experiments with the same subject of ten gave different results. Figures 10 and 11 , for example, show the results of inflations at intervals of a few minutes in Case 14. In other cases pain appeared first in one situation but if the balloon was left in situ without further inflation sensations developed in other perhaps widely separate regions. 


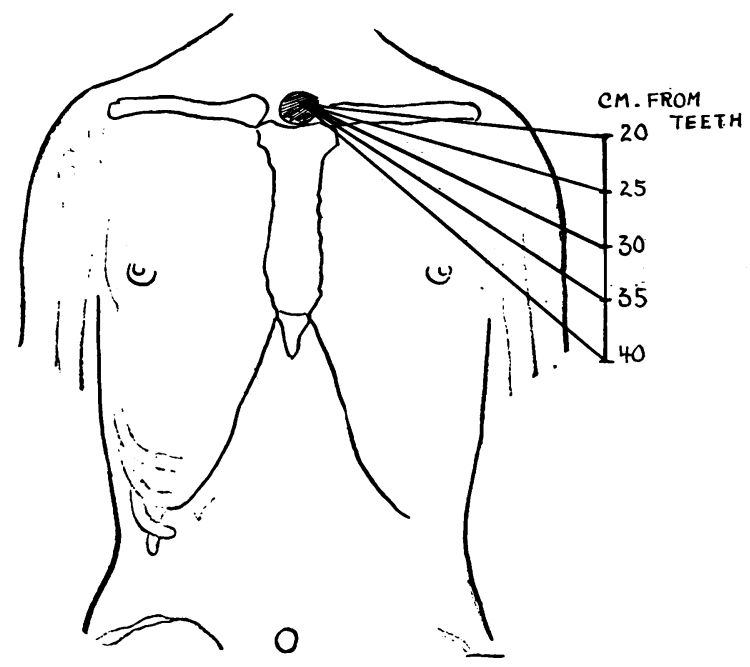

Fig. 3. (Case 2.) In This as in the Following Diagrams the Figures in the Margin Indicate the Level of the Balloon; the Lines Run to the Area of Referred Pain.

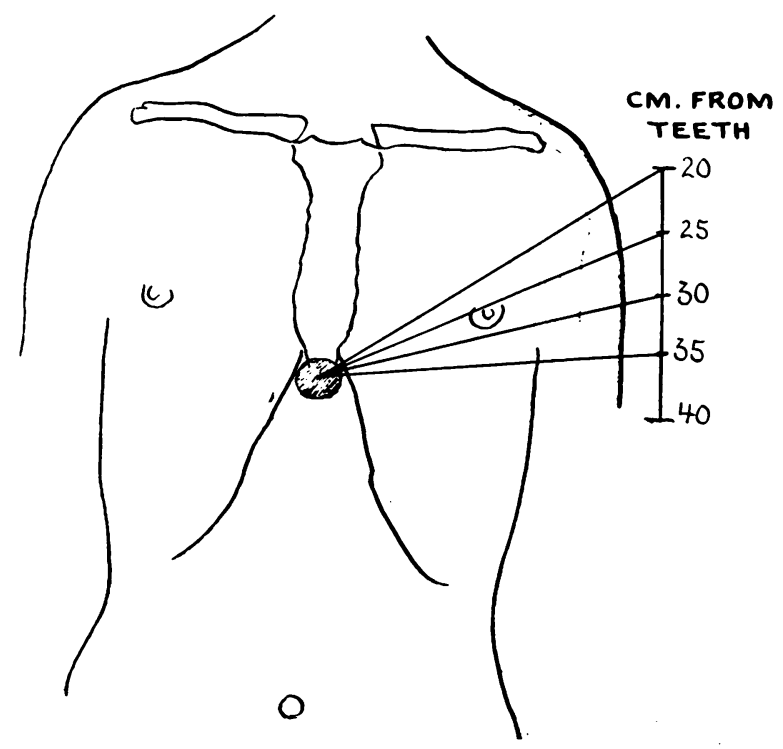

FIG. 4. (CASE 36) 


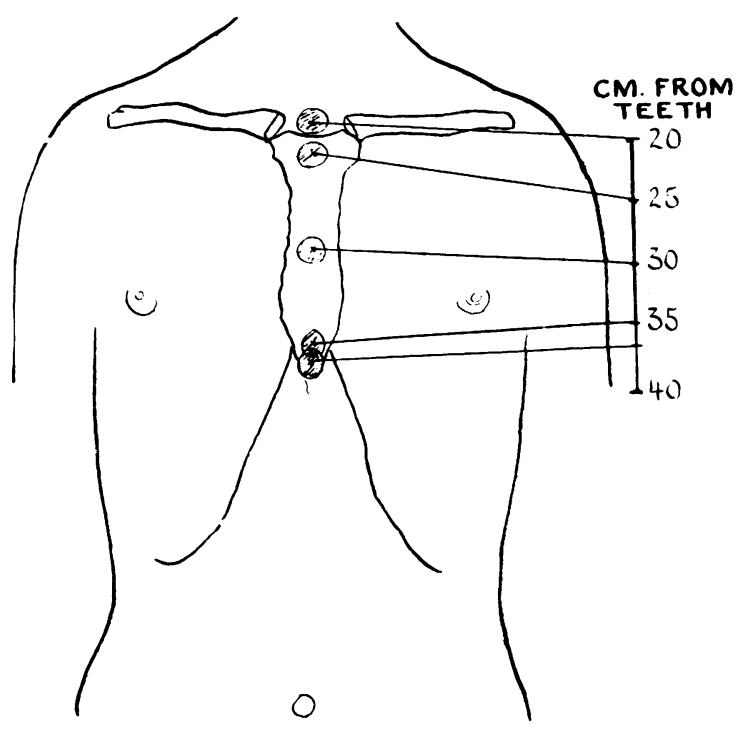

FIG. 5. (CASE 21)

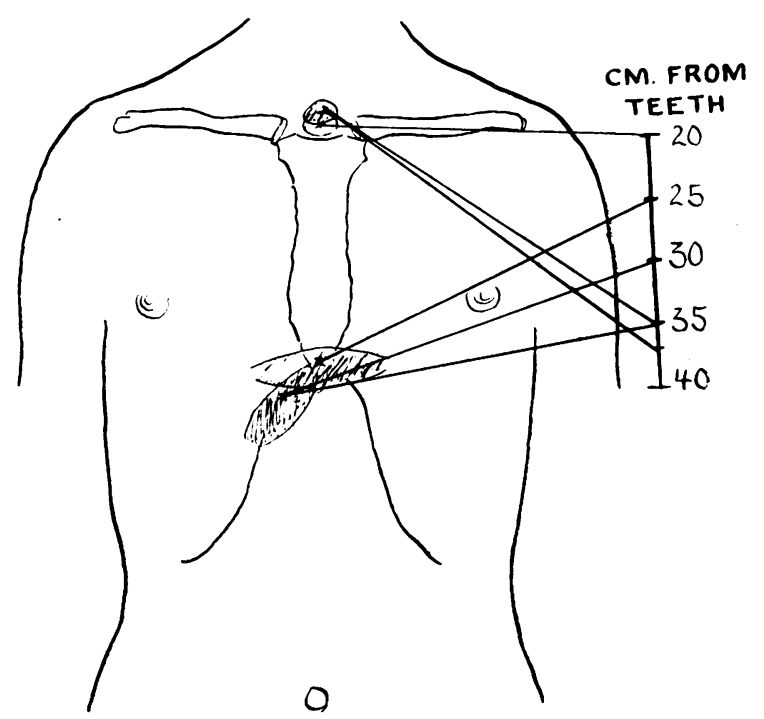

FIg. 6. (CASE 7) 


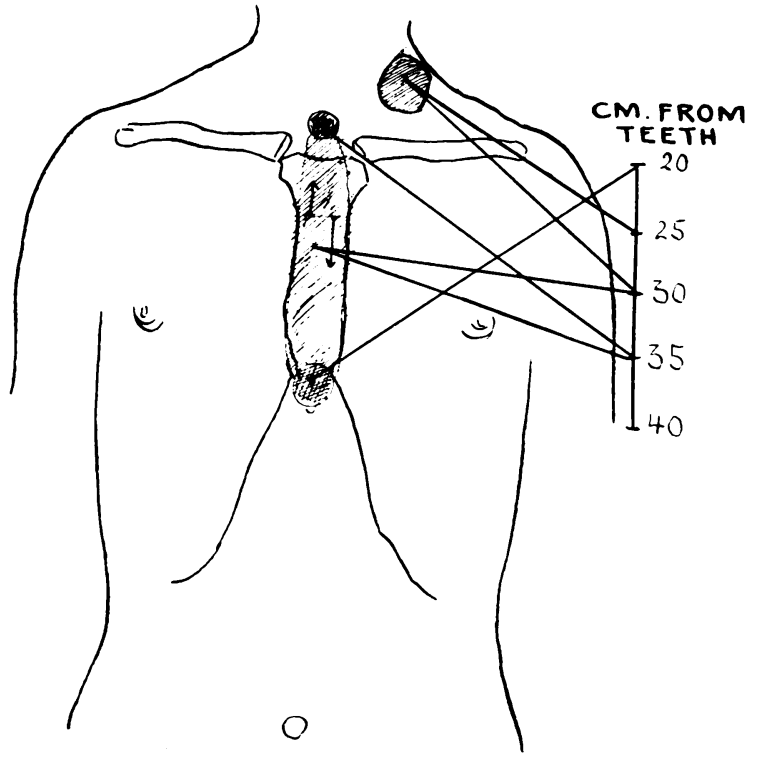

Fig. 7. (CASE 25)

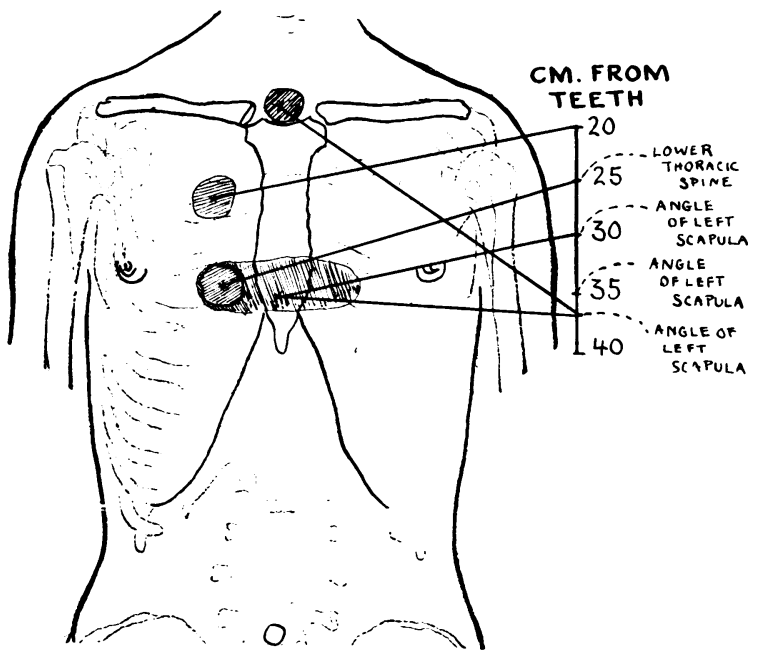

FIG. 8. (CASE 34) 


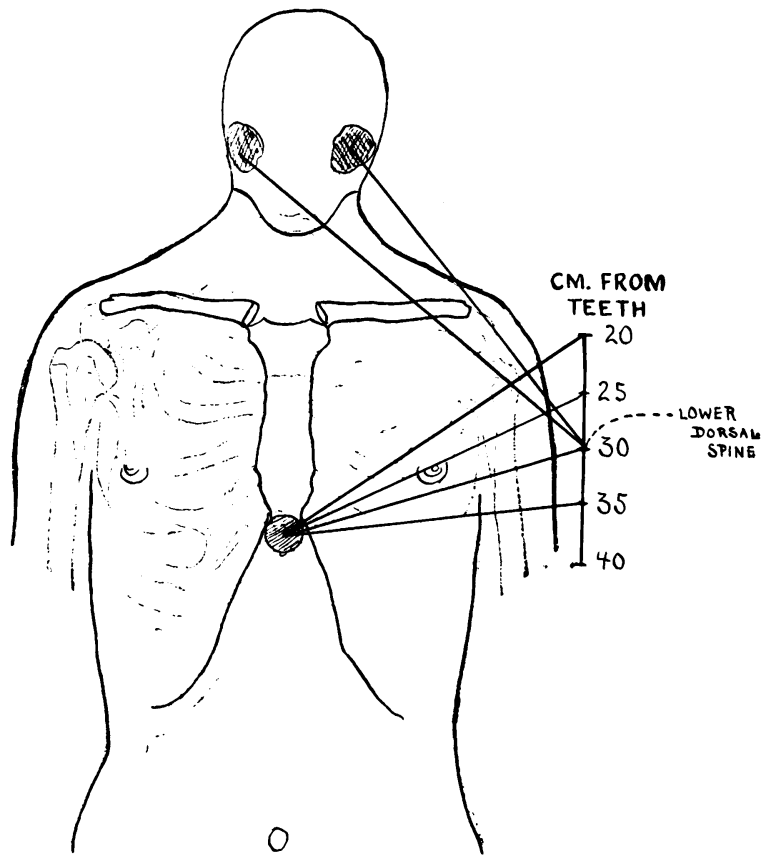

FIG. 9. (CASE 29)

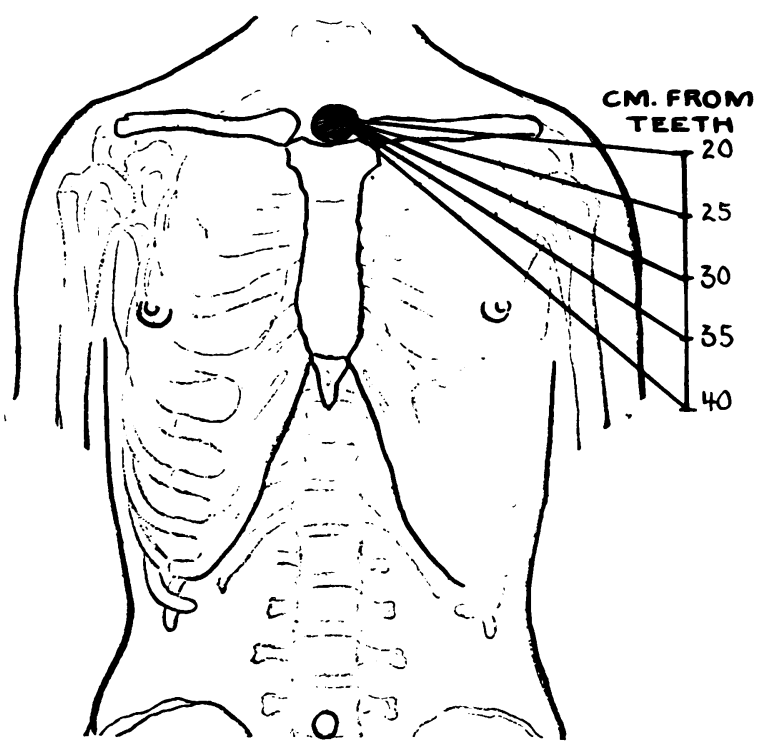

Fig. 10. (CASE 14-First Test) 


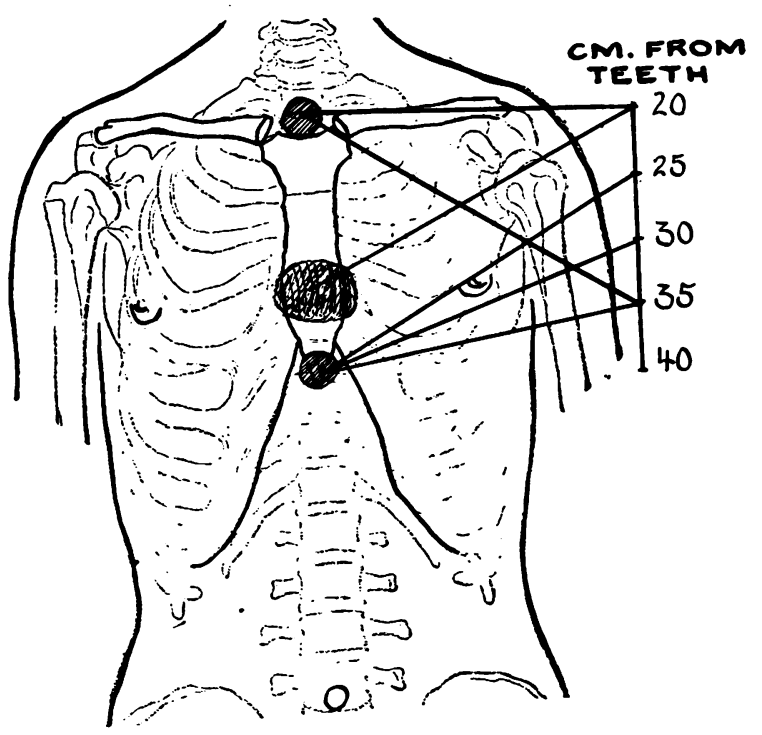

Fig. 11. (CASE 14-Second Test)

THE INTENSITY OF THE STIMULUS NECESSARY TO PRODUCE PAIN

One object of the present work was to use standard stimuli so that differences in sensitiveness in different people could be determined. To this end air was introduced into the standard balloon at a constant rate of $2 \mathrm{cc}$. per second. The results were, however, so variable that no really quantitative information was obtained. But in most of the subjects pain was felt after 15 to $25 \mathrm{cc}$. of air had been introduced with a resulting pressure of from 80 to $150 \mathrm{~mm}$. $\mathrm{Hg}$. Two typical cases are shown in Table III. An attempt was made to correlate the

TABLE III

Amount of air and pressure necessary to produce pain

\begin{tabular}{|c|c|c|c|c|}
\hline \multirow{3}{*}{$\begin{array}{l}\text { Level of balloon } \\
\text { from teeth }\end{array}$} & \multicolumn{2}{|c|}{ Case 6} & \multicolumn{2}{|c|}{ Case 8} \\
\hline & \multicolumn{2}{|c|}{ Pain felt with air } & \multicolumn{2}{|c|}{ Pain felt with air } \\
\hline & Volume & Pressure & Volume & Pressure \\
\hline $\begin{array}{l}c m . \\
20\end{array}$ & $\begin{array}{l}c c . \\
18\end{array}$ & $\begin{array}{c}m m . H g \\
140\end{array}$ & $\begin{array}{l}c c . \\
20\end{array}$ & $\begin{array}{c}m m . H g \\
100\end{array}$ \\
\hline 25 & 19 & 130 & 14 & 90 \\
\hline 30 & 26 & 140 & 15 & 90 \\
\hline 35 & 25 & 140 & 22 & 90 \\
\hline
\end{tabular}


threshold stimulus with the general nervous make-up of the subjects, the presence of spontaneous gastro-intestinal symptoms and general sensitiveness to pain, but no relations could be discovered except in occasional instances. Case 9, for example, who had a mild cardiospasm failed to have pain on inflation until an unusually large amount of air (25-30 cc.) had been introduced when the pressure stood at only 80 $\mathrm{mm}$. Hg. Case 34 required $50 \mathrm{cc}$. of air and then only felt a slight sensation of "contraction." This man was in general rather insensitive to pain and did not react to pressure over the supraorbital nerves.

No relation was discovered between the degree of stimulus necessary to produce pain and the type of gastric secretion.

\section{THE CHARACTER OF THE REFERRED SENSATIONS}

The most striking feature of the referred sensations was the inability of the patient as a rule to describe them exactly. On the whole they seemed to fall under the heading of pain although with minimal stimuli no great distress was usually produced. The subjects own descriptions (Table IV) give a better idea of the situation than any general statement. In some cases after eliciting sensation with the minimal stimulus the balloon was further inflated. This usually resulted in definite distress, sometimes very severe, although the character of the sensation in general remained unchanged. In Cases 38 and 39 nausea was a striking feature of the reaction to inflation of the esophagus. This sensation was, however, much less frequent than in the case of the stomach or duodenum as will be pointed out later. It was difficult to define the referred sensations in relation to body surface and while the subjects pointed to a fairly definite location, either in front or in back, the pain was usually described as being inside rather than superficial.

TABLE IV

Character of pain from inflation of esophagus

Case 1 A deep burning.

2 Lump in neck which would not go up or down.

3 Pain like a lump-not very severe.

4 "A stretch, a tight feeling."

5 Felt like "a prickly pear down there."

6 "A pressure, no pain but it hurt."

7 Felt like "something was going to bust." 
8 A painful distended feeling.

9 "Pressure."

10 "Pain."

11 "A hurt." Neither fullness nor burning .

12 "Uncomfortable pressing feeling."

13 "Terrible gas pressure."

14 "Pain."

15 "Pain."

16 Feels like "finger nail against a hot stove"-a wave of pain.

17 "Kind of suffocating pain, like one wanted to take breath and couldn't."

18 "A sharp burning pain."

19 Slight sensation of a "lump."

20 "Painful pressing."

21 "Burning, gnawing pain."

22 "Something pushing out."

23 "A sharp little pain."

24 "Pain."

25 "Burning sensation."

26 "Just like gas pains, only stronger."

27 "Feels like big piece of potato down there, hurts a little."

28 "Like something was pushing out on me, something heavy."

29 An "ache."

30 "Pressing."

31 "Sort of pressure against a sore place."

32 "Severe dull ache."

33 "Pain.

34 "Contraction."

35 "Sharp tingling pain."

36 "Something sharp."

37 "A pressing."

38 Pain-nausea.

39 "Just a little sore like." Nausea.

RELATION OF "ARTIFICIAL" TO SPONTANEOUS PAIN

A good many of the subjects had digestive disorders and an attempt was made to relate the sensations produced by inflation to their spontaneous symptoms. The results of this inquiry are shown in Table V.

TABLE V

Relation of spontaneous discomfort to artificial referred pain

Case
2
6
7
8
9

"Spontaneous Symptoms"

"Artificial Symptoms"

Epigastric distress, gas and nausea

Indigestion (duodenal ulcer)

Indigestion (duodenal ulcer)

Unlike spontaneous

Epigastric distress

Unlike spontaneous

Epigastric distress and gas (cardiospasm)

Unlike spontaneous

Unlike spontaneous

Felt like spontaneous pain but less marked 
12

16

22

26

27

28

31

35
Pain and fullness in epigastrium after eating (cancer of stomach)

Indigestion and "heart-burn"

Pain in upper abdomen $1 / 2$ to 1 hour p.c. Relieved by vomiting (gallstones)

Epigastric distress (duodenal ulcer)

Epigastric distress (duodenal ulcer)

Indigestion-discomfort radiating to left shoulder

Epigastric distress (duodenal ulcer)

Epigastric distress (duodenal ulcer)
Unlike spontaneous

Exactly like spontaneous.

Unlike spontaneous

Unlike spontaneous

Pain produced at xyphoid is identical with the spontaneous distress

Exactly like spontaneous pain

Unlike spontaneous pain

Like spontaneous pain but milder

In five of these thirteen cases inflation of the esophagus reproduced the patient's spontaneous discomfort. It seems highly likely, therefore, that some of the epigastric discomforts encountered clinically and the symptoms classed as "heart-burn" may originate in reflex contractions or spasms of the esophagus, a view which has already been proposed by others.

\section{NATURE OF THE REFERRED PAIN}

The sensations which have been described in the preceding sections might conceivably originate locally at the site of the stimulus or they might be referred to the superficies by way of vagus or sympathetic. We soon abandoned the idea of local pain in view of the lack of correlation between the site of the balloon and the position of the pain and because of the variable results from repeated stimuli at a given point. The surface area which includes all pain referred from the esophagus is innervated from the 3 rd cervical to the 7 th or 8 th dorsal segments. It seems highly likely that the sensations produced over sternum anterior chest wall and back are referred via the sympathetic to corresponding skin segments. The explanation of the suprasternal notch pain which occurred so commonly is less clear. If of sympathetic origin the 3rd cervical segment would be implicated and if so it seems remarkable that pain in the arms (C4 to D3) never occurred. The writers do not feel that their understanding of the physiology of the autonomic system is sound enough for them to pursue the discussion further; let it be sufficient to record the facts.

The possibility of distension of the esophagus at any one point 
setting up reflex spasm elsewhere along the tube had to be considered as a possible explanation of pain which appeared at sites remote from the stimulus. We have no exact data as to this mechanism but it seems an unlikely one inasmuch as pain wherever produced invariably disappeared instantaneously as soon as the balloon was deflated.

\section{DISCUSSION}

The experiments described above show that it is possible to produce referred pain by inflation of small balloons in the esophagus. Such pain occurred, contrary to the findings of Hertz and of Payne and Poulton, without relation to the position of the bag in the esophagus and over a wide area of the torso and occasionally in the neck or face although the suprasternal notch and the xyphoid region were sites of predilection. The experimental findings were especially illuminating in connection with what has been observed in patients with esophageal disease. A recent case of carcinoma of the esophagus, for example, with the stricture just above the cardia complained after taking food of distress confined to the suprasternal notch and relieved by vomiting. In other clinical cases pain has been confined to the back as in some of the experimental subjects. Of especial interest were the patients with spontaneous epigastric distress associated with peptic ulcer whose symptoms were reproduced by inflation of the esophagus (Table V), a finding which suggests that reflex spasm of the esophagus may play a part in the production of "ulcer indigestion" in certain cases. At any rate familiarity with the areas over which pain may be referred experimentally from the esophagus is clearly useful in interpreting the diagnostic problems of clinical cases. With regard to the type of the referred sensations the vagueness of the descriptions is noteworthy and agrees with our experience in eliciting histories from patients. One evidently deals with an elementary form of discomfort which can not be accurately defined. It is of interest that sensations akin to clinical "heart-burn" were produced in a number of instances; obviously regurgitation of acid played no part here and this too agrees with clinical experience that heart-burn may occur in patients with absence of acid in the gastric secretions. "The "burning" may therefore be a characteristic of the referred sensation quite apart from the back flow of acid into the esophagus which of course occurs in many patients. 
From the standpoint of exact physiological observation the results of the present study are disappointing; indeed we question whether phenomena of the sort with which we were dealing lend themselves to quantitative exploration. With every effort to standardize stimuli and to make the experimental conditions as objective as possible great variation occurred in the effects induced in the same subject on repeated tests-variations which occurred almost from moment to moment and which depended not only on psychic factors, but on the ever changing conditions of tonus and motility which are encountered in a hollow viscus.

\section{SUMMARY}

1. Inflation of small balloons in the esophagus produces referred sensations (pain).

2. The site of the referred pain bears no relation to the position of the balloon but occurs especially at the xyphoid or in the suprasternal notch, and less often over the anterior chest wall or in the back. Rarely it was felt in the neck or face and in two cases nausea was produced.

3. The character of the sensation was crude and of ten could not be accurately described or delineated by the subject. It frequently was identical with spontaneous "digestive" discomforts.

4. No relation was made out between the subject's general susceptibility to pain and the ease with which referred pain was produced.

5. The bearings of these observations on clinical diagnosis are discussed.

\section{BIBLIOGRAPHY}

1. Mackenzie, James, Symptoms and Their Interpretation. London, 1909.

2. Hertz, A. F., The Sensibility of the Alimentary Canal. London, 1911.

3. Carlson, A. J. and Braafladt, L. H., Am. J. Physiol., 1915, xxxvi, 153. Contributions to the Physiology of the Stomach. XVIII. On the Sensibility of the Gastric Mucosa.

4. Payne, W. W. and Poulton, E. P., Quart. J. Med., 1923-24, xvii, 53. Visceral Pain in the Upper Alimentary Tract.

5. Payne, W. W. and Poulton, E. P., J. Physiol., 1927, 1xiii, 217. Experiments on Visceral Sensation. I. The Relations of Pain to Activity in the Human Oesophagus.

6. Payne, W. W. and Poulton, E. P., J. Physiol., 1928, 1xv, 157. Experiments on Visceral Sensation. II. The Sensation of "Nausea" and "Sinking"; Oesophageal Reflexes and Counter-Irritation.

7. Jones, C. M., (personal communication). 